\title{
PREMATURE DESTRUCTION OF TWO-SPAN RC BEAMS EXPOSED TO HIGH TEMPERATURE CAUSED BY A REDISTRIBUTION OF SHEAR FORCES
}

\author{
Robert KOWALSKI ${ }^{\mathrm{a}}$, Michał GŁOWACKI ${ }^{\mathrm{a}}$, Marian ABRAMOWICZ ${ }^{\mathrm{b}}$ \\ ${ }^{a}$ Institute of Building Engineering, Faculty of Civil Engineering, Warsaw University of Technology, \\ 16 Armii Ludowej Str., 00-637 Warsaw, Poland \\ ${ }^{b}$ Construction Safety Department, Fire Safety Engineering Faculty, Main School of Fire Service in Warsaw, \\ 52/54 Stowackiego Str., 01-629 Warsaw, Poland
}

Received 23 Sep 2014; accepted 29 Oct 2015

\begin{abstract}
When multi-span RC elements are exposed to fire one usually observes a yielding of span cross-sections while a safety reserve of support cross-sections is still significant. Due to this phenomenon a redistribution of bending moments occurs and the values of sagging moment in span cross-sections decrease while the values of hogging moment in support cross-sections increase. This paper shows the results of tests conducted on two-span RC beams in a situation when only one span has been exposed to high temperature from the bottom. The beams were $12 \times 16 \mathrm{~cm}$ in their crosssection. The length of the span was $165 \mathrm{~cm}$. The load has been applied by two forces put on each span. The beams were made of C25/30 concrete with siliceous aggregate. As a result of significant stiffness decrease of the heated span, redistribution of shear forces and bending moment occurs. Due to this redistribution the tested beams were prematurely damaged due to exhaust of the shear load bearing capacity in the middle part of the beam span where there was no transverse reinforcement.
\end{abstract}

Keywords: two-span beams, reinforced concrete, fire, high temperature, redistribution, shear forces, bending moments, shear resistance, stiffness.

\section{Introduction}

Exposed to fire, reinforced concrete (RC) elements exhibit a significant reduction in load capacity and stiffness. This is caused by a decrease in the mechanical properties of concrete and reinforcing steel due to high temperature (EN 1992-1-2 2004; fib Bulletin 38 2007; fib Bulletin 46 2008; Colina et al. 2004; Abramowicz, Kowalski 2005; Bednarek, Kamocka 2006; Hertz 2004; Kodur 2014). During fire the slabs or beams are usually heated only from the bottom face. In this case only the tensile zone of the element (reinforcement) in the span region and the compressed zone in the support are heated. Stiffness of a cross-section with heated tensile zone decreases much faster than in a cross-section with heated compressed zone (EN 1992-1-2 2004; Kowalski 2008; Kowalski et al. 2013, 2015).

In multi-span elements this phenomenon leads to redistribution of internal forces resulting in a reduction of sagging moments and an increase of hogging moments (EN 1992-1-2 2004; fib Bulletin 46 2008; Kordina 2010; Kowalski, Urbański 2013; Scott, Whittle 2005; Bednarek 2003; El-Fitiany, Youssef 2014; Dwaikat, Kodur 2008).
Simultaneously, a redistribution of shear forces occurs, increasing the risk of shear load bearing capacity loss (Arslan 2012; Xiang et al. 2013).

Additionally, during the first heating a concrete thermal transient creep usually occurs simultaneously with a decrease in the cross-section stiffness and free concrete thermal elongation (Khoury 2006; Mindeguia et al. 2013; Sadaoui, Khennane 2012). As a result of the transient creep concrete might shorten or elongate, depending on the concrete compressive stress (Gernay, Franssen 2010).

The main goal of this paper is to present an experimental study of the redistribution of shear forces and bending moments in two-span loaded RC beams, in case when, only one span is exposed to high temperature from the bottom face. In the tested beams redistribution of shear forces was observed, leading to premature beam destruction due to shear. The experimental results were then compared to simplified calculations based on Eurocode (EN 1992-1-2 2004). Temperature distribution in the cross-section of beams was determined based on measured values supplemented by Finite Element Method (FEM) calculations. 


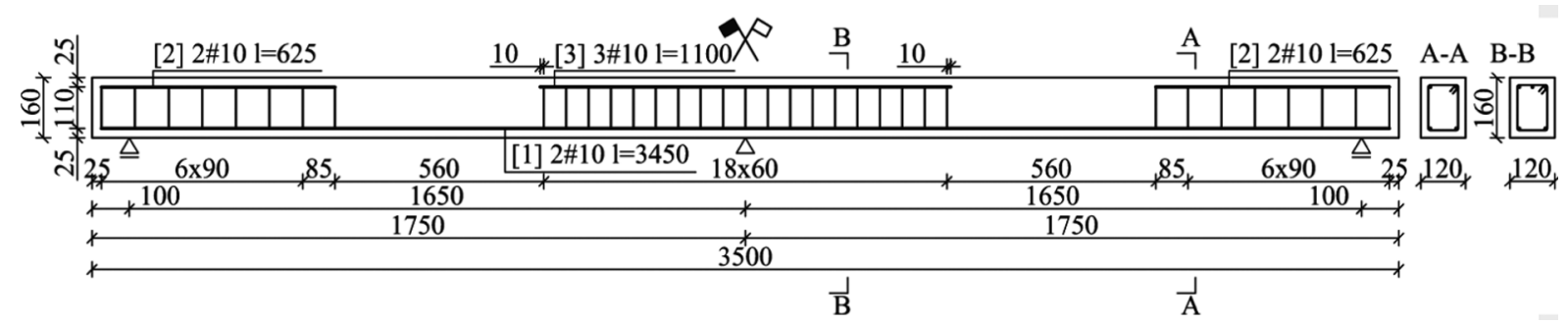

Fig. 1. Tested beams

\section{Experiment description}

\subsection{Elements}

Two two-span RC beams with rectangular cross-section $\mathrm{b} \times \mathrm{h}=120 \times 160 \mathrm{~mm}$, span of $1650 \mathrm{~mm}$ and total length of $3500 \mathrm{~mm}$ (Fig. 1) were tested.

Concrete with siliceous gravel aggregate was used (for detailed composition of the concrete mixture see Table 1). The average concrete compressive strength measured 28 days after casting on a $150 \times 150 \times 150 \mathrm{~mm}$ cube was $34.5 \mathrm{MPa}$. This classified concrete as $\mathrm{C} 25 / 30$. The high temperature experiments were conducted 5 months after beams casting when concrete average compressive strength reached $43.8 \mathrm{MPa}$ and concrete moisture content gained $4.2 \%$.

According to EN 1992-1-2 (2004), in case when moisture content in concrete exceeds $3 \%$, concrete thermal spalling may occur. However, in this experiment this phenomenon was not observed, despite the higher moisture content.

Table 1. Concrete mixture (for $1 \mathrm{~m}^{3}$ of concrete)

\begin{tabular}{c|l|c}
\hline No. & \multicolumn{1}{|c}{ Component } & $\mathrm{kg} / \mathrm{m}^{3}$ \\
\hline 1 & Water & 97 \\
\hline 2 & Cement CEM II B-V 32.5R & 314 \\
\hline 3 & Sand 0-2 mm & 768 \\
\hline 4 & Siliceous gravel 2-8 mm & 548 \\
\hline 5 & Siliceous gravel 8-16 mm & 664 \\
\hline 6 & Fly ash & 62 \\
\hline 7 & Chemical additives & 1 \\
\hline & Total & 2454 \\
\hline
\end{tabular}

The main beam reinforcement was made of B500SP steel bars produced in Poland with guaranteed yield strength of $500 \mathrm{MPa}$. The average yield strength was experimentally determined to be $590 \mathrm{MPa}$. The span reinforcement was made of two $10 \mathrm{~mm}$ bars (reinforcement ratio $\rho_{1}=0.97 \%$ ) while in the intermediate support three bars of $10 \mathrm{~mm}$ diameter $\left(\rho_{1}=1.45 \%\right)$ were used. Stirrups made of St0S-b 6-mm-diameter steel were placed at spacing of $90 \mathrm{~mm}$ at end supports and $60 \mathrm{~mm}$ at the intermediate support. Concrete cover was made in a way that the main reinforcement axis distance was $25 \mathrm{~mm}$ from the element's face.

\subsection{Testing procedure}

The beams were loaded with two forces placed on each span at $1 / 3$ of their length (Fig. 2). Before high temperature tests each beam was loaded and unloaded eight times to $60 \%$ of its ultimate load capacity. This value was calculated on the basis of real material properties. Concrete compressive strength was taken as $0.8 \times 43.8=35.0 \mathrm{MPa}$. $80 \%$ of cube strength (at the time of the test) might be applied as a cylindrical (real) strength. Steel yield strength was taken as $590 \mathrm{MPa}$ (average value of the test results).

Pre-loading elements before high temperature tests was done to simulate real structural conditions. The $60 \%$ load level might be considered appropriate as quasi-permanent load level in many practical cases. Based on previous research (Kowalski 2008), loading and unloading the specimen 8 times is enough because between $6^{\text {th }}$ and $8^{\text {th }}$ load cycle both a crack pattern and deflection of a tested beam usually stabilises. Due to cracks, stiffness of the tested beam is close to the real conditions (cracked cross-sections stiffness). Cracks formed as a result of pre-loading, do not have any influence on reinforcement temperature during heating as long as cracks widths are small. However, big cracks (up to $2-3 \mathrm{~mm}$ width) begin to form only when reinforcement temperature is high and the beam is close to load capacity loss.

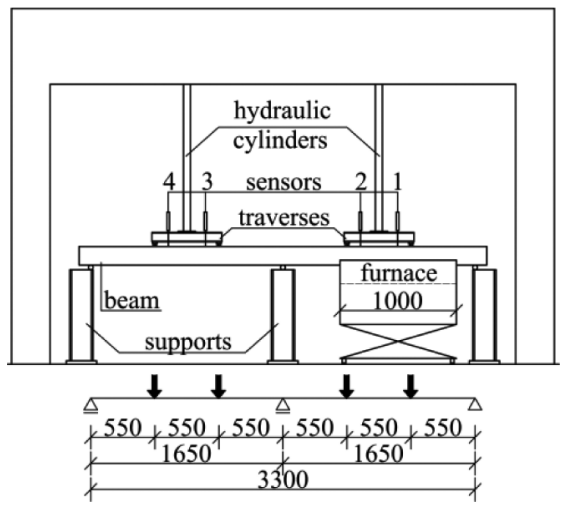

Fig. 2. Diagram of the experimental setup

According to calculations performed on the basis of real material properties, the beam loaded with the load equal to calculated load capacity (bending) has relatively big shear capacity reserve:

- $40 \%$ at the end support region (with stirrups; Fig. 1); 
- $20 \%$ at the intermediate support region (with stirrups);

- $70 \%$ in the middle part of the span (no stirrups).

After 8 load-unload cycles, the beam was loaded with $60 \%$ of its calculated load capacity (a quasi-permanent load level in many practical cases). A furnace heated previously to the temperature of $350{ }^{\circ} \mathrm{C}$ was slid under the bottom face of the beam (see Figs 2 and 3). The furnace temperature increased to $850{ }^{\circ} \mathrm{C}$ in the subsequent 40 minutes (Fig. 4).

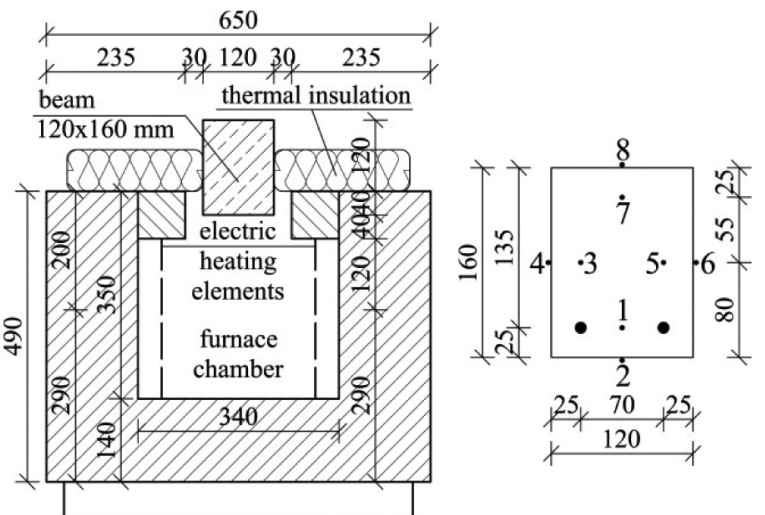

Fig. 3. Location of the beam in the furnace and thermocouples placement in the beam cross-section

During the tests the following parameters were measured:

- time of heating;

- beam deflection, at four points (see Fig. 2);

- support reactions;

- temperature in mid-span cross-section of the beam, Figure 3 shows thermocouples placement.

\section{Discussion of experiment run}

The tests were conducted until the beams were destroyed which happened after 56 and 65 min of heating. Figure 4 shows variation of temperature in the furnace chamber and at particular cross-section points of tested beams. It should be noted that the thermal conditions inside the furnace chamber were comparable to those described by the standard fire curve (EN 1991-1-2 2002).

The temperature at the bottom face (T2) did not significantly differ between the two beams; while the lateral surfaces of the beam 1 (T4 and T6) were heated slightly faster than in case of the beam 2. At the time of destruction the temperature in the tensile zone of the beam 1 (T1) exceeded $500{ }^{\circ} \mathrm{C}$ but in the beam 2 it was a little bit lower. Beam 1 was destroyed about 10 minutes earlier than beam 2. However, the beams were destroyed due to shear load bearing capacity loss, not as the result of the yielding of the main reinforcement.

Figure 5 shows the deflection of the tested beams, measured at two points of the heated span (sensors 1 and 2, Fig. 2) and at two points of the not heated span (sensors 3 and 4). The heated span deflected significantly while the unheated span deflected slightly upwards. The deflection growth was approximately linear.

Figure 6 shows the relative changes of support reactions. It should be noted that in the applied static scheme the reactions at both end supports are independent of the beam stiffness and are always equal to each other.

Figure 7 shows distribution of bending moments and shear forces in the tested beams: before the beginning of heating (blue line), after 20 minutes of heating (red line) and just before the beam destruction (green line).

Due to heating there was a gradual decrease of the sagging moments and an increase of the hogging moments. A similar phenomenon was observed for shear forces. The shear forces at the ending supports decreased while the shear forces in the middle section of the span and at the intermediate support increased.

Figure 8 shows relative changes of extreme sagging and hogging moments during heating. As a result of redistribution of bending moments, caused by the decrease of stiffness of heated beam span, the hogging moment increased by $65-75 \%$, while the sagging moment decreased by $25-30 \%$.

b)

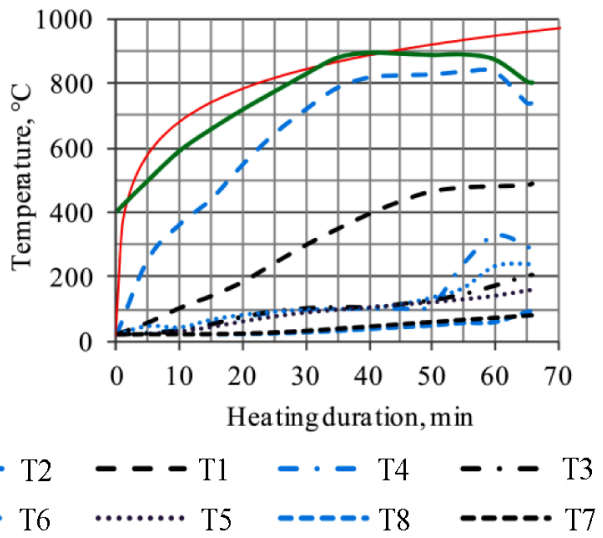

Fig. 4. Variation of temperature in the furnace and at different thermocouples locations (T1-T8, see Fig. 3) with time: a) beam 1, b) beam 2 


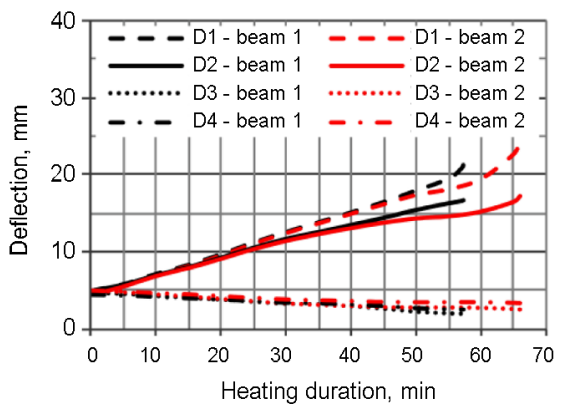

Fig. 5. Deflection of the beams: D1, D2 - at heated span, D3, D4 - at not heated span (sensors location - see Fig. 2)

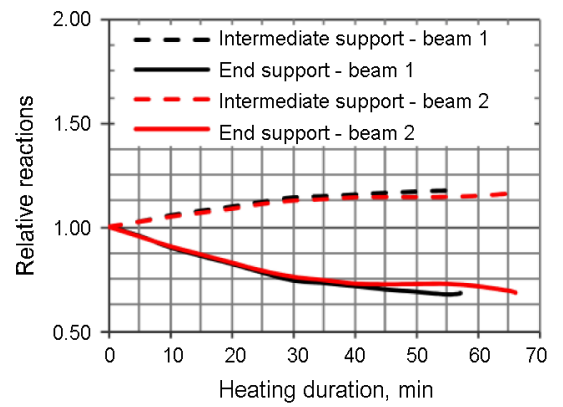

Fig. 6. Relative changes of support reactions: intermediate and end support

Figure 9 shows relative changes of shear forces in the middle section of the span and at the intermediate and end supports. As a result of shear forces redistribution, a significant shear force increase was observed in the middle section of the span (by about $75 \%$ ). Shear forces at the intermediate support slightly increased (by

a)

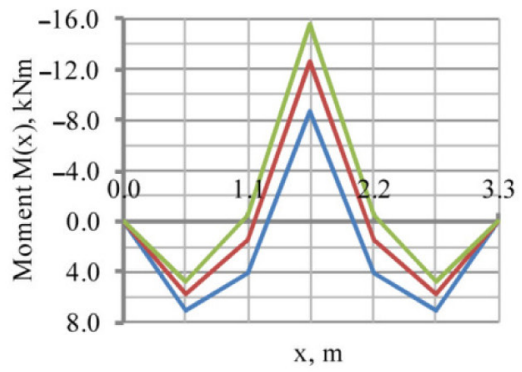

c)

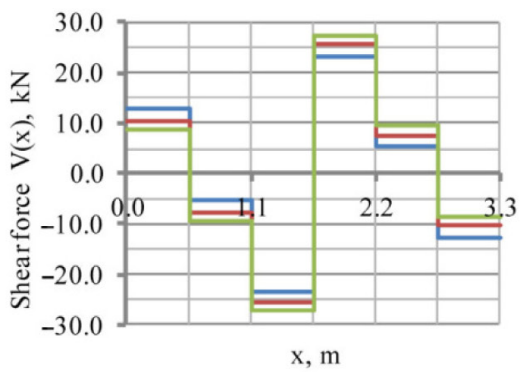

- Before heating

After 20 min. of heating about $12-15 \%$ ) while at the end supports decreased (by about $25-27 \%$ ).

\section{Temperature distribution in the beam cross-section}

During the tests the temperature was measured at particular points (see Fig. 3) in a cross-section situated at the middle of the heated span of the beam. The obtained temperature values were used for verification of calculations of unsteady heat flow in the beam cross-section performed with Finite Element Method (FEM). Calculations results provided with an isotherms layout in the cross-section of the beam and the temperature of reinforcing bars.

The thermocouples were put into the beam crosssection after casting. In order to enable a precise placement of the thermocouples as well as their multiple use, they were placed through $5 \mathrm{~mm}$ holes drilled in concrete. Then the holes were filled with fine grained dry sand and chopped with rock wool.

When the temperature is measured in the abovementioned way, it is impossible to directly measure the temperature of bars. If a thermocouple was placed within the beam before casting it would be impossible to guarantee that it would not move. This causes that it is difficult to measure bar temperature directly. When there is even a small gap (fully filled by concrete) between the thermocouple and the bar surface (the thermocouple does not touch the surface of the bar) the reading of reinforcement temperature might be falsified. It might too high if the thermocouple is placed closer to the heated element surface than the bar or it would be too low if the thermocouple was situated in the middle part of the cross-

b)

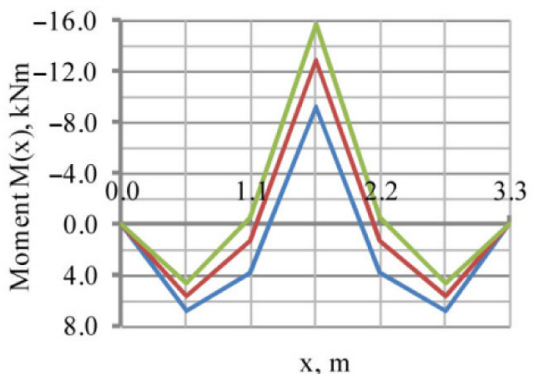

d)

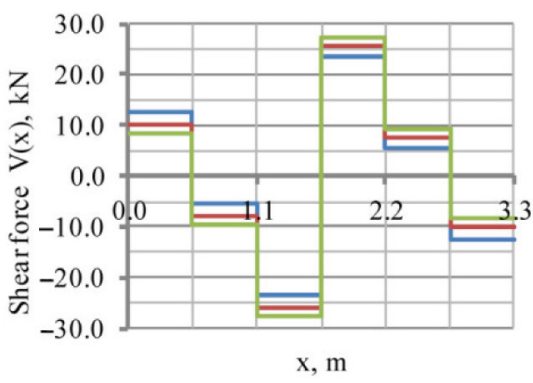

After $56(65) \mathrm{min}$. of heating - just before destruction

Fig. 7. a), b) Bending moments in two beams in subsequent heating stages, c), d) shear forces in two beams in subsequent heating stages; beam destruction occurred after 56 min (beam 1) and 65 min (beam 2) of heating 


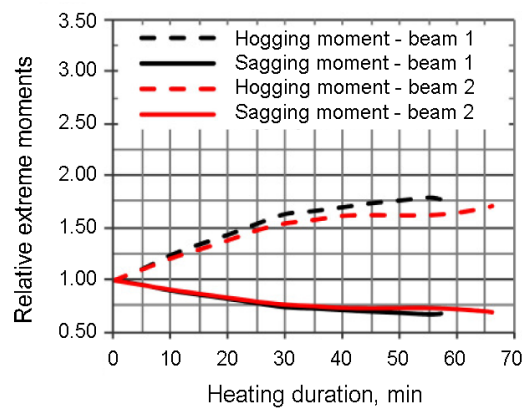

Fig. 8. Relative changes of extreme bending moments: hogging and sagging

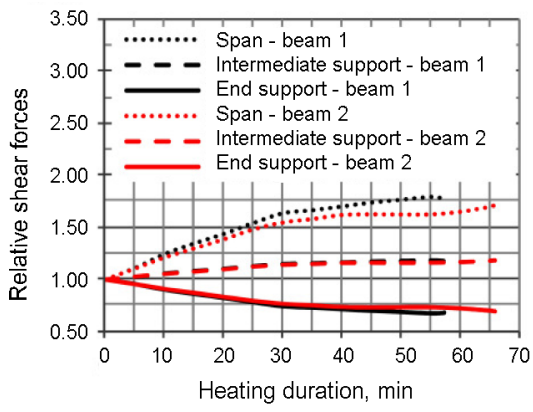

Fig. 9. Relative changes of shear forces: in the middle section of the span and at supports: intermediate and end

section. Therefore, in these tests the temperature of bars was not measured directly.

In order to perform the unsteady heat flow calculations inside the RC cross-section, concrete thermal conductivity and concrete specific heat must be known. To determine the heat penetrating into the beam crosssection through its surface one should consider both the convection and the radiation heat flux. Basic information on how to model these fluxes can be found in EN 1991-1-2 (2002). However, there is no reason to assume that conditions in electric furnace are similar to fire conditions described in EN 1991-1-2 (2002).

Therefore in the performed calculations the heat flux penetrating through the beam surface was not used as a boundary condition. Instead, the temperature values measured directly at the beam surface (T2, see Figs 3 and 4) were used as an input data for the calculation of unsteady heat flow inside of the beam cross-section.
The calculations were performed with ANSYS software. Concrete thermal conductivity and concrete specific heat were taken from EN 1992-1-2 (2004) for concrete with $3 \%$ moisture content. Additionally, real concrete density $\left(2454 \mathrm{~kg} / \mathrm{m}^{3}\right)$ was used.

Two dimensional model of the beam cross-section, made of eight node quadrangle elements with side width of approximately $0.5 \mathrm{~cm}$ was considered. The longitudinal reinforcing bars were modelled according to corresponding steel thermal properties (EN 1993-1-2 2005).

It was assumed that only the bottom face of the beam cross-section and the bottom $40 \mathrm{~mm}$ of both lateral faces were heated (Fig. 10e).

Figures 10a-10d show isotherms in the cross-section of the beam calculated after 15, 30, 45 and 60 minutes of heating.

Figure 11 shows comparison between the calculated and the measured values of the temperature at the points of the cross-section where the temperature was measured. For the position $\mathrm{T} 3$ and $\mathrm{T} 4$ the measured values were taken as the average of two thermocouples.

The calculated temperature values are very close to the measured. Thus, it can be concluded that concrete thermal properties taken from EN 1992-1-2 (2004) are good enough for modelling of the temperature distribution in the tested beams.

Additionally, in Figure 11 the temperature values calculated for points where reinforcing bars are situated were plotted as red triangles.

\section{Analysis of test results}

Before the beginning of heating the bending moment at the intermediate support in both beams was equal to $60 \%$ of the calculated cross-section load bearing capacity. However, in the final heating stage the bending moment reached $99 \%(0.60 \times 1.65)$ of the load bearing capacity in beam 1 and $105 \%(0.60 \times 1.75)$ in beam 2 (Fig. 8). Thus, in the final stage of beams testing the cross-section at the middle support was very close to the ultimate limit state.

In the heated span cross-section a decrease of load bearing capacity, caused by an increase in reinforcement temperature, occurred simultaneously with a decrease of the bending moment resulting from the redistribution of internal forces. In the final heating stage the bending moment at the span cross-section was estimated at ap- a)

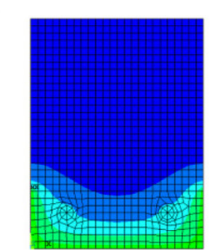

b)

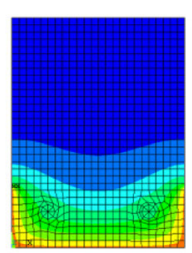

c)

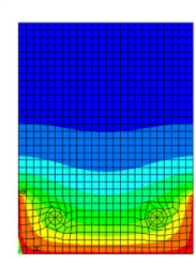

d)

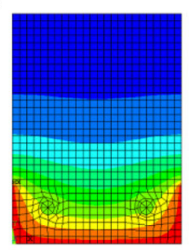

e)

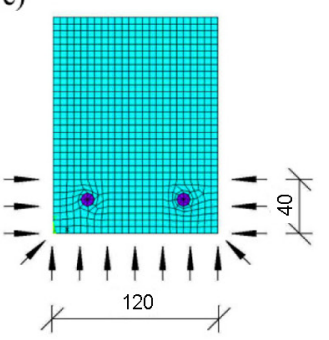

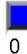

100
200

300
400

500

600

700

800 900

Fig. 10. Calculated isotherm layout in the cross section $(120 \times 160 \mathrm{~mm})$ of the beam: a) heating duration $-15 \mathrm{~min}, \mathrm{~b}) 30 \mathrm{~min}$, c) $45 \mathrm{~min}$, d) $60 \mathrm{~min}, \mathrm{e}$ ) a part of the beam face exposed to high temperature 


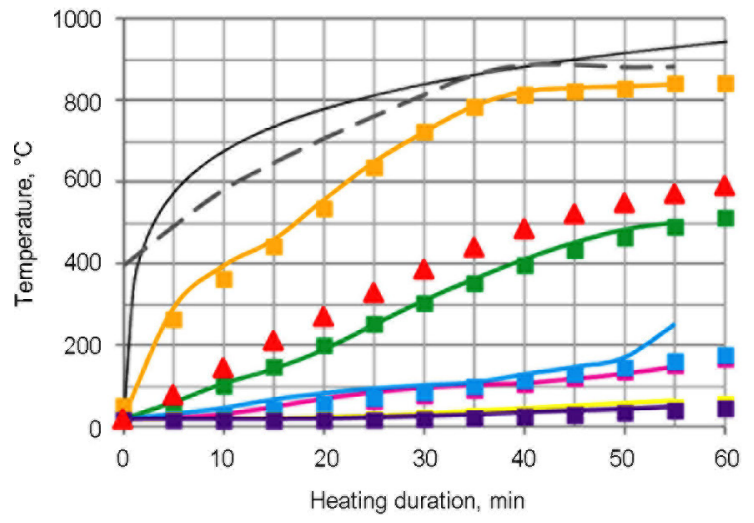

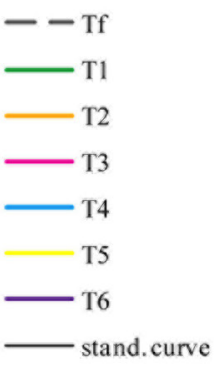

$\triangle$ Reinf.FEM

- T1 FEM

- T2 FEM

- T3 FEM

- T4 FEM

1- T5 FEM

- T6 FEM

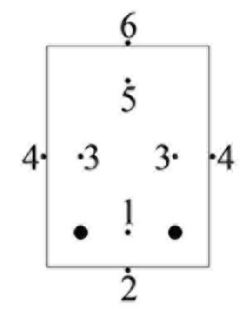

$\mathrm{Tf}$ - temperature in furnace chamber;

$\mathrm{T} 1, \mathrm{~T} 2, \mathrm{~T} 5, \mathrm{~T} 6$ - temperature at points 1, 2, 5, 6;

T3, T4 - average values of temperature at points located symmetrical to the cross-section vertical axis; standard fire curve- according to (EN 1991-1-2 2002)

Fig. 11. Temperature in the beam cross section - comparison of experimental results and FEM calculations; lines represent experimental data, markers show FEM calculated results

proximately $42 \%(0.60 \times 0.70)$ of the load bearing capacity at room temperature in the case of beam 1 and $45 \%$ $(0.60 \times 0.75)$ in case of beam 2 .

This lead to a conclusion that the tensile zone of the span cross-section heated to about $600{ }^{\circ} \mathrm{C}$ (see Fig. 11) was also very close to load bearing capacity loss.

However, based on the crack pattern on the beams (Fig. 12), it can be concluded that not the bending moment, but the loss of shear load bearing capacity in the cross-section situated in the middle part of the heated span was a direct cause of the beam destruction.

Table 2 shows a comparison between the shear forces occurring in particular zones of the tested beams and calculated load bearing capacity: before heating (at room temperature) and just before the beam destruction.

Shear load bearing capacity at room temperature in intermediate and ending support zones $V_{R d, s}$ were calculated with the formula (EN 1992-1-1 2008):

$$
V_{R d, s}=\frac{A_{s w}}{s} z f_{y w d} \cot \theta,
$$

where: $A_{s w}$ - the cross-sectional area of the shear reinforcement; $s$ - stirrups spacing; $z$ - the lever arm of internal forces; $f_{y w d}$ - the design yield strength of the shear reinforcement; $\theta$ - the angle between the concrete compression strut and the beam axis perpendicular to the shear force.

Table 2. Comparison of calculated shear load bearing capacity and shear forces occurred in tested beams

\begin{tabular}{lccc}
\hline & $\begin{array}{c}\text { Intermediate } \\
\text { support zone } \\
\mathrm{kN}\end{array}$ & $\begin{array}{c}\text { Span } \\
\text { zone, } \\
\mathrm{kN}\end{array}$ & $\begin{array}{c}\text { Ending } \\
\text { support zone, } \\
\mathrm{kN}\end{array}$ \\
\hline $\begin{array}{l}\text { Load bearing capacity } \\
\text { at room temperature }\end{array}$ & 50.3 & 18.5 & 33.6 \\
\hline $\begin{array}{l}\text { The force before } \\
\text { heating }\end{array}$ & 23.5 & 5.5 & 12.5 \\
\hline $\begin{array}{l}\text { The force just before } \\
\text { a destruction }\end{array}$ & 27.5 & 9.5 & 8.5 \\
\hline
\end{tabular}

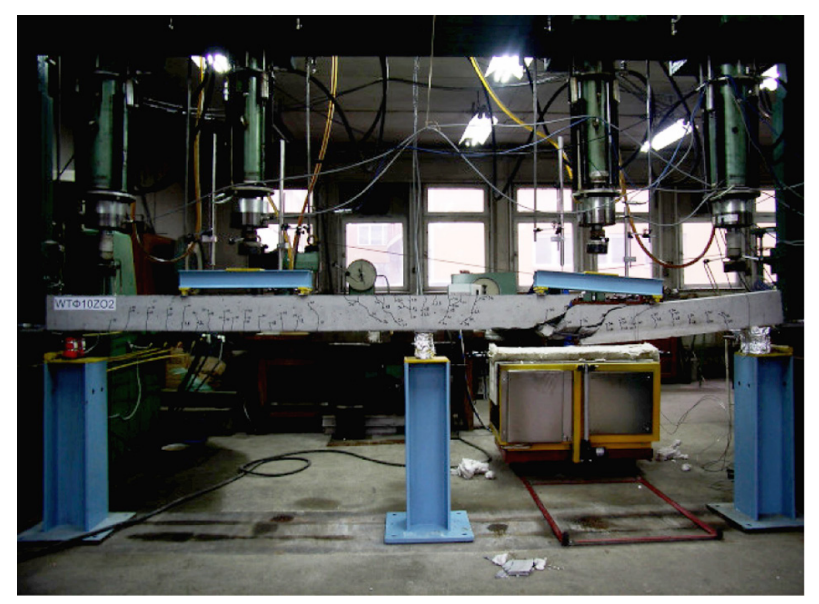

Fig. 12. The destroyed beam no. 1

Shear load bearing capacity in the middle span of the beam $V_{R d, c}$ was calculated with the formula:

$$
V_{R d, c}=\left[C_{R d, c} k\left(100 \rho_{l} f_{c k}\right)^{1 / 3}\right] b_{w} d,
$$

where: $C_{R d, c}$ and $k$-are factors; $\rho_{l}$ - the reinforcement ratio for longitudinal reinforcement; $f_{c \mathrm{c}}-$ the characteristic concrete compressive strength; $b_{w}$ - the cross-section width; $d$ - the effective depth of a cross-section.

Before the beginning of heating, there was a significant reserve of shear load bearing capacity in the tested beams. As a result of redistribution of internal forces caused by the heating, the shear force in the middle part of the heated span of the beam increased by about $75 \%$. The increased shear force reached about $51 \%$ of the initial cross-section shear load bearing capacity (at room temperature). However, this load capacity decreased significantly due to heating. As a result of concrete degradation in the bottom part of the beam its active cross-section ("shear working") was significantly reduced. Furthermore, the reduction of shear load bearing capacity could also be caused by elongation of the main reinforcing bars. Their temperature reached about $600{ }^{\circ} \mathrm{C}$ (Fig. 11). 
Table 3. Calculation data and calculated shear load bearing capacity of the cross-section situated in the middle part of the beam

\begin{tabular}{lccc}
\hline & $\begin{array}{c}500{ }^{\circ} \mathrm{C} \text { Isotherm method, } \\
\text { formula (3) }\end{array}$ & $\begin{array}{c}500{ }^{\circ} \mathrm{C} \text { Isotherm method, } \\
\text { formula (4) }\end{array}$ & $\begin{array}{c}\text { Zone method, } \\
\text { formula (4) }\end{array}$ \\
\hline Calculation data & $\begin{array}{l}C_{R d, c}=0.18, k=2.0, \\
\rho_{l}=1.31 \%, f_{c k}=35 \mathrm{MPa}, \\
b_{w}=12 \mathrm{~cm}, d_{f i}=10 \mathrm{~cm}\end{array}$ & $\begin{array}{l}C_{R d, c}=0.18, k=2.0, \\
\rho_{l}=1.74 \%, f_{c t k}=2.25 \mathrm{MPa}, \\
b_{w}=12 \mathrm{~cm}, d_{f i}=7.5 \mathrm{~cm}\end{array}$ & $\begin{array}{l}C_{R d, c}=0.18, k=2.0, \\
\rho_{l}=1.74 \%, f_{c t k, f}=1.44 \mathrm{MPa}, \\
b_{w}=12 \mathrm{~cm}, d_{f i}=7.5 \mathrm{~cm}\end{array}$ \\
\hline $\begin{array}{l}\text { Shear load bearing capacity } \\
\text { at high temperature, } \mathrm{kN}\end{array}$ & 15.5 & 12.8 & 10.2 \\
\hline $\begin{array}{l}\text { Shear load bearing capacity } \\
\text { at room temperature, } \mathrm{kN}\end{array}$ & & 18.5 & \\
\hline $\begin{array}{l}\text { Shear force just before the } \\
\text { beam destruction, } \mathrm{kN}\end{array}$ & & 9.5 & \\
\hline
\end{tabular}

\section{Estimation of shear load bearing capacity at high temperature}

As it was described above, the destruction of the beams was caused by the loss of the shear load bearing capacity in the middle section of the heated span of the beam, where there were no stirrups. The redistribution of shear forces due to heating resulted in an increase of shear force in the middle section of the heated span of the beam from 5.5 to $9.5 \mathrm{kN}$ (by about 73\%). The calculated initial (room temperature) shear load bearing capacity in this part of the beam was equal to $18.5 \mathrm{kN}$ (Table 2), but it decreased significantly due to high temperature exposure.

The estimation of the shear load bearing capacity in the middle section of the heated span of the beam (without stirrups) at high temperature just before the destruction of the beam is presented below.

Calculations were performed using three different methods in accordance with EN 1992-1-2 (2004):

$-500{ }^{\circ} \mathrm{C}$ Isotherm method, taking into account the concrete compressive strength;

$-500{ }^{\circ} \mathrm{C}$ Isotherm method modified in a way that the value of concrete tensile strength was considered instead of the compressive strength;

- Modified Zone method based on reduced concrete tensile strength.

Calculation results and the most important data used for calculations are summarised in Table 3.

Both, the $500{ }^{\circ} \mathrm{C}$ Isotherm and the Zone method are applicable only for standard fire exposure (EN 1992-1-2 2002). However, they could have been used because the temperature increase in the furnace chamber (Fig. 11) was close to the standard curve.

In calculations performed using the $500{ }^{\circ} \mathrm{C}$ Isotherm method, it was assumed that the concrete layer with temperature exceeding $500{ }^{\circ} \mathrm{C}$ does not influence the crosssection load bearing capacity while the remaining part of the beam maintains its initial compressive strength (as at room temperature). The shear load bearing capacity was calculated with the formula (3) (EN 1992-1-1 2008). Isotherm $500{ }^{\circ} \mathrm{C}$ layout was determined based on FEM calculations (Fig. 10):

$$
V_{R d, c, f i}=\left[C_{R d, c} k\left(100 \rho_{l} f_{c k}\right)^{1 / 3}\right] b_{w} d_{f i} .
$$

In calculations performed using the modified $500{ }^{\circ} \mathrm{C}$ Isotherm method cross-section shear load bearing capacity depended on concrete tensile strength. The isotherm separating active and destroyed parts of the cross-section was determined to be equal to the temperature at which the concrete tensile strength decreases as the concrete compressive strength at $500{ }^{\circ} \mathrm{C}$. It is known that in the temperature of $500{ }^{\circ} \mathrm{C}$ the compressive strength of concrete with siliceous aggregate decreases by $40 \%$ (EN 1992-1-2 2004). The same reduction in concrete tensile strength occurs at the temperature of $300{ }^{\circ} \mathrm{C}$ (EN 1992-1-2 2004). Therefore, in order to estimate the shear load bearing capacity it was assumed that the "destroyed" concrete with temperature exceeding $300{ }^{\circ} \mathrm{C}$, does not influence crosssection load bearing capacity.

In calculations performed using the Zone method the outer layer of the cross-section, which was entirely destroyed due to heating, was excluded from the analysis. To determine its thickness, the cross-section was divided into 16 parallel zones and the average temperature at the middle of each zone was calculated. A concrete tensile strength reduction coefficient $\left(k_{c, t}(\theta)\right)$ was determined for each zone, based on the calculated temperature values. Finally, the mean value of concrete tensile strength reduction coefficient $\left(k_{c, t}(\theta)\right)$ for the whole cross-section was calculated and the thickness of the destroyed zone was determined.

In calculations performed using the modified $500{ }^{\circ} \mathrm{C}$ Isotherm method and the Zone method the shear load bearing capacity at high temperature was calculated with the formula (4). This formula was obtained by substituting into the Eqn (3) the relationship (5) which connects concrete compressive strength $\left(f_{c k}\right)$ with concrete tensile strength $\left(f_{c t k}\right)$ (EN 1992-1-1 2008):

$$
\begin{gathered}
V_{R d, c, f i}=\left[C_{R d, c} k\left(100 \rho_{l} \sqrt{\left(\frac{f_{c t k}}{0.7 \cdot 0.3}\right)^{3}}\right)^{\frac{1}{3}}\right] b_{w} d_{f i} ; \\
f_{c t k}=0.7 \cdot 0.3 f_{c k}^{\frac{2}{3}} .
\end{gathered}
$$

The best prediction was obtained using the Zone method (Table 3). The value of shear load bearing capacity of the cross-section at high temperature estimated with 
this method was greater than the one obtained experimentally by only $7 \%(10.2$ and $9.5 \mathrm{kN})$. The values calculated with the two other methods significantly exceeded the experimental result. This confirms that the Zone method is more suitable for predicting fire load bearing capacity of small cross-sections. Additionally, it can be noted that when determining shear load bearing capacity of a crosssections without transverse reinforcement, one should consider that due to high temperature concrete tensile strength decreases much faster than concrete compressive strength.

\section{Conclusions}

The results confirmed the occurrence of a significant redistribution of internal forces in two-span loaded beams exposed to high temperature. In the examined elements the hogging moment increased by about $65-75 \%$ and the sagging moment decreased by about $25-30 \%$.

However, the destruction of the tested beams happened not due to the bending but as a result of shear load bearing capacity loss in the middle part of the heated span of the beam. This destruction mechanism may appear a little surprising because before heating the shear load bearing capacity reserve was significant (approximately triple). However, as a result of shear forces redistribution, the shear force in the middle part of the heated span of the beam increased by about $75 \%$, and the cross-section load bearing capacity was reduced approximately by half.

The redistribution of bending moments and shear forces in the tested beams was caused by the two most important phenomena: reduction in stiffness of the heated span and thermal elongation of concrete in the heated zone.

The performed calculations have shown that the best estimate of the shear load bearing capacity can be obtained with the Zone method.

From a practical structural fire design point of view, it must be noted that in some conditions the destruction of multi-span RC elements might occur due to the redistribution of internal forces resulting in significant increase of shear force in zone where it was very small before a fire exposure.

\section{References}

Abramowicz, M.; Kowalski, R. 2005. The influence of short time water cooling on the mechanical properties of concrete heated up to high temperature, Journal of Civil Engineering and Management 11(2): 85-90. http://dx.doi.org/10.1080/13923730.2005.9636336

Arslan, G. 2012. Diagonal tension failure of RC beams without stirrups, Journal of Civil Engineering and Management 18(2): 217-226. http://dx.doi.org/10.3846/13923730.2012.671264

Bednarek, Z. 2003. Effect of redistribution of internal forces on fire resistance of flexural reinforced concrete members, Journal of Civil Engineering and Management 9(4): 266270. http://dx.doi.org/10.1080/13923730.2003.10531338

Bednarek, Z.; Kamocka, R. 2006.The heating rate impact on parameters characteristic of steel behaviour under fire conditions, Journal of Civil Engineering and Management 12(4): 269-275.
Colina, H.; Moreau, G.; Cintra, D. 2004.Experimental study of transient thermal creep and other phenomena of concrete at high temperature, Journal of Civil Engineering and Management 10(4): 255-260. http://dx.doi.org/10.1080/13923730.2004.9636317

Dwaikat, M. B.; Kodur, V. K. R. 2008. A numerical approach for modelling the fire induced restraint effects in reinforced concrete beams, Fire Safety Journal 43(4): 291307. http://dx.doi.org/10.1016/j.firesaf.2007.08.003

El-Fitiany, S. F.; Youssef, M. A. 2014. Simplified method to analyze continuous reinforced concrete beams during fire exposure, ACI Structural Journal 111(1): 145-156.

EN 1992-1-1 Eurocode 2: Design of concrete structures Part 1-1: General rules and rules for buildings. European Committee for Standardization, Brussels, 2008.

EN 1991-1-2 Eurocode 1: Actions on structures - Part 1-2: General actions - Actions on structures exposed to fire. European Committee for Standardization, Brussels, 2002.

EN 1992-1-2 Eurocode 2: Design of concrete structures Part 1-2: General rules - Structural fire design. European Committee for Standardization, Brussels, 2004.

EN 1993-1-2 Eurocode 3: Design of steel structures - Part 1-2: General rules - Structural fire design. European Committee for Standardization, Brussels, 2005.

fib Bulletin 38/2007. Fire design of concrete structures - materials, structures and modelling. The International Federation for Structural Concrete, 2007.

fib Bulletin 46/2008. Fire design of concrete structures - structural behaviour and assessment. The International Federation for Structural Concrete, 2008.

Gernay, T.; Franssen, J.-M. 2010. Consideration of transient creep in the Eurocode constitutive model in the fire situation, in Proceedings of the Sixth International Conference Structures in Fire, 2-4 June 2010, Michigan State University, USA, 784-791.

Hertz, K. D. 2004. Reinforcement data for fire safety design, Magazine of Concrete Research 56(8): 453-459. http://dx.doi.org/10.1680/macr.2004.56.8.453

Khoury, G. A. 2006 Strain of heated concrete during two thermal cycles. Part 3: Isolation of strain components and strain model development, Magazine of Concrete Research 58(7): 421-435. http://dx.doi.org/10.1680/macr.2006.58.7.421

Kodur, V. K. R. 2014. Properties of concrete at elevated temperatures, ISRN Civil Engineering. Article ID 468510. 15 p. (in press). http://dx.doi.org/10.1155/2014/468510

Kordina, K. 2010. Design of concrete buildings for fire resistance, Chapter 6 in Structural Concrete. Textbook on behaviour, design and performance. $2^{\text {nd }}$ ed. Vol. 4. fib Bulletin 54. The International Federation for Structural Concrete.

Kowalski, R. 2008. Load bearing capacity calculation of bent $R C$ elements in fire. Publishing House of The Warsaw University of Technology (in Polish).

Kowalski, R.; Abramowicz, M.; Głowacki, M. 2013. Influence of high temperature on stiffness of R/C Beams. Experimental stiffness comparison of tensioned or compressed zone of the cross-section, in Proceedings of International Conference Applications of Structural Fire Engineering, 19-20 April 2013, Prague, Czech Republic, 307-313.

Kowalski, R.; Głowacki, M.; Abramowicz, M. 2015. On the experimental analysis of temperature influence on stiffness of reinforced concrete beams, Journal of Structural Fire Engineering 6(1): 49-57. http://dx.doi.org/10.1260/2040-2317.6.1.49

Kowalski, R.; Urbański, M. 2013. On the redistribution of bending moments in two-span RC beams and slabs exposed to fire, Journal of Civil Engineering and Architecture 7(2): 158-173. 
Mindeguia, J.-C.; Hager, I.; Pimienta, P.; Carre, H.; La Borderie, C. 2013. Parametrical study of transient thermal strain of ordinary and high performance concrete, Cement and Concrete Research 48: 40-52. http://dx.doi.org/10.1016/j.cemconres.2013.02.004

Sadaoui, A.; Khennane, A. 2012. Effect of transient creep on behavior of reinforced concrete beams in a fire, $A C I$ Materials Journal 109(6): 607-616.
Scott, R. H.; Whittle, R. T. 2005. Moment redistribution effects in beams, Magazine of Concrete Research 57(1): 9-20. http://dx.doi.org/10.1680/macr.2005.57.1.9

Xiang, K.; Wang, G. H.; Zhao, B. 2013. Finite element analysis of shear strength of reinforced concrete beams after fire, in Y. Huang et al. (Eds.). Advanced Materials Research, Chapter 2: Structural engineering 671-674: 474-478. http://dx.doi.org/10.4028/www.scientific.net/AMR.671674.474

Robert KOWALSKI. PhD, DSc, Civ. Eng., Associate Professor. Warsaw University of Technology, Faculty of Civil Engineering, Concrete Structures Department. Charted engineer, licensed special expert in the field of building structures. Scientific and engineering interests: influence of fire on concrete structures, concrete structures.

Michal GLOWACKI. MSc, Civ. Eng., Teaching Assistant. Warsaw University of Technology, Faculty of Civil Engineering, Concrete Structures Department. Scientific and engineering interests: influence of fire on concrete structures, concrete structures.

Marian ABRAMOWICZ. PhD, DSc, Civ. Eng., Full Professor. Main School of Fire Service, Warsaw. Head of Building Safety Department. Retired Professor of Warsaw University of Technology, Faculty of Civil Engineering. Scientific and engineering interests: fire safety, influence of fire on concrete structures, concrete structures. 